\title{
Patterns and Trends of Herbal Medicine Use among Patients with Gynecologic Cancer
}

\author{
Die Verwendung pflanzlicher Arzneimittel durch Patientinnen \\ mit gynäkologischen Krebserkrankungen: Muster und Tendenzen
}

(c) (1) $\ominus$

Authors

Anna-Katharin Theuser ${ }^{1}$, Carolin C. Hack², Peter A. Fasching ${ }^{2}$, Sophia Antoniadis ${ }^{2}$, Katharina Grasruck², Sonja Wasner², Stefanie Knoll2 ${ }^{2}$, Hartwig Sievers ${ }^{3}$, Matthias W. Beckmann², Falk C. Thiel ${ }^{4}$

\section{Affiliations}

1 Institute for Women's Health/Institut für Frauengesundheit $\mathrm{GmbH}$, Erlangen, Germany

2 Department of Gynecology and Obstetrics, Comprehensive Cancer Center Erlangen - European Metropolitan Area Nuremberg (CCC ER-EMN), University Hospital Erlangen, Friedrich-Alexander-Universität Erlangen-Nürnberg, Erlangen, Germany

3 PhytoLab GmbH \& Co. KG, Vestenbergsgreuth, Germany

4 Department of Gynecology and Obstetrics, Alb Fils Kliniken, Klinik am Eichert, Göppingen, Germany

\section{Key words}

cancer, gynecologic oncology, herbal medicine, integrative medicine, complementary and alternative medicine

\section{Schlüsselwörter}

Krebs, gynäkologische Onkologie, pflanzliche Arzneimittel, integrative Medizin, alternative und komplementäre Medizin

\section{received}

accepted after revision

20.4.2021

Bibliography

Geburtsh Frauenheilk 2021; 81: 699-707

DOI 10.1055/a-1487-6284

ISSN 0016-5751

(C) 2021. The Author(s).

This is an open access article published by Thieme under the terms of the Creative Commons Attribution-NonDerivative-NonCommercial-License, permitting copying and reproduction so long as the original work is given appropriate credit. Contents may not be used for commercial purposes, or adapted, remixed, transformed or built upon. (https://creativecommons.org/licenses/by-nc-nd/4.0/)

Georg Thieme Verlag KG, Rüdigerstraße 14,

70469 Stuttgart, Germany

\section{Correspondence}

Anna-Katharin Theuser, PhD

Institute for Women's Health/Institut für Frauengesundheit

$\mathrm{GmbH}$

Universitätsstraße 21-23, 91054 Erlangen, Germany

anna-katharin.theuser@ifg-erlangen.de

( ) Supplementary material is available under https://doi.org/10.1055/a-1487-6284

\section{ABSTRACT}

Background More and more information about complementary and integrative medicine is becoming available, especially among cancer patients. However, little is known about the use of herbal medicine by patients with gynecologic cancers. This study aimed to assess the use of herbal products by gynecologic cancer patients compared with healthy controls. Methods This cross-sectional study was conducted at the Department for Gynecology and Obstetrics of Erlangen University Hospital and included 201 patients with gynecologic cancer and 212 healthy controls. Use of herbal medicines was evaluated using a standardized questionnaire. Medical information on cancer patients was collected from hospital records. Group comparisons were done using a logistic regression model. Risk ratios were assessed using a Poisson regression model.

Results Gynecologic cancer patients used herbal medicine significantly less often than healthy persons. $69 \%$ of gynecologic cancer patients and $81 \%$ of healthy participants reported using herbal products. $40 \%$ of cancer patients and $56 \%$ of healthy persons reported using plants for medicinal purposes. Motives of cancer patients for using herbal medicine included treatment of cancer-related symptoms. The major source of information for both groups was family and friends.

Conclusions Although herbal medicine was used less by patients with gynecologic cancer, herbal products were used by both cancer patients and healthy individuals. To provide cancer patients with optimal therapy, oncologists should be in- 
formed about the herbal products used by their patients as this will allow them to take their patients' self-medication with herbal medicine into account. Counseling by oncologists on the use of herbal medicine should be encouraged.

\section{ZUSAMMENFASSUNG}

Hintergrund Immer mehr Informationen zu integrativer und komplementärer Medizin sind verfügbar, besonders für Krebspatienten. Noch ist aber wenig über die Verwendung von pflanzlichen Arzneimitteln durch Patientinnen mit gynäkologischem Krebs bekannt. Ziel dieser Studie war es, mehr über die Verwendung pflanzlicher Mittel durch Patientinnen mit gynäkologischem Krebs im Vergleich mit einer gesunden Kontrollgruppe zu erfahren.

Methoden Diese Querschnittsuntersuchung wurde an der Abteilung für Gynäkologie und Geburtshilfe, Universitätsklinikum Erlangen durchgeführt. 201 Patientinnen mit gynäkologischem Krebs und 212 gesunde Kontrollpersonen wurden in die Studie aufgenommen. Die Verwendung von pflanzlichen Arzneimitteln wurde anhand eines standardisierten Fragenbogens evaluiert. Die medizinischen Daten zu den Krebspatientinnen wurden den Krankenhausakten entnommen. Gruppenvergleiche wurden mithilfe eines logistischen Regressionsmodells durchgeführt. Ein Poisson-Regressionsmodell wurde verwendet, um Risikoquoten auszuwerten.
Ergebnisse Patientinnen mit gynäkologischem Krebs verwendeten pflanzliche Arzneimittel signifikant weniger als die gesunden Frauen in der Kontrollgruppe. 69\% der Patientinnen mit gynäkologischem Krebs und $81 \%$ der gesunden Teilnehmerinnen gaben an, pflanzliche Produkte zu benutzen. $40 \%$ der Krebspatientinnen und 56\% der gesunden Personen gaben an, dass sie pflanzliche Produkte für medizinische Zwecke verwendeten. Die Behandlung von krebsbedingten Symptomen war einer der von den Krebspatientinnen angegebenen Gründe für die Verwendung von pflanzlichen Arzneimitteln. Die Hauptinformationsquellen für beide Gruppen waren Familie und Freunde.

Schlussfolgerungen Obwohl pflanzliche Arzneimittel weniger oft von Patientinnen mit gynäkologischem Krebs eingenommen werden, verwenden sowohl Krebspatientinnen als auch gesunde Personen pflanzliche Produkte. Um Krebspatientinnen eine optimale Therapie zu ermöglichen, sollten Onkologen über die von ihren Patientinnen verwendeten pflanzlichen Mittel informiert werden, damit sie die zur Selbstbehandlung verwendeten pflanzlichen Arzneimittel berücksichtigen können. Eine Beratung zum Einsatz von pflanzlichen Arzneimitteln durch den Onkologen sollte gefördert werden.

\section{Introduction}

More and more information is becoming available about the use of complementary and alternative medicine (CAM) or integrative medicine by patients with cancer. Surveys of patients with gynecologic cancer have shown that approximately $40-50 \%$ of patients use some form of CAM [1-4]. The majority of CAM remedies, such as vitamins, herbal medicine, or plant extracts, are taken orally [2,3]. Herbal medicines and herbal supplements are among the most popular CAM products. A systematic literature review on the use of herbal supplements in the United Kingdom reported that up to $22 \%$ of cancer patients were taking herbal supplements [5].

Reasons given by patients for using CAM, including herbal medicines, included treatment of cancer-related symptoms and improvement of quality of life [6].

Herbal medicine is an integral part of Western traditional medicine. According to the definition of the World Health Organization (WHO), herbal medicines include types of medicine that use herbs or herbal materials, herbal preparations, and finished herbal products containing parts of plants or materials made from plants as the active ingredient [7]. In Germany, certain forms of traditional herbal medicine such as homeopathy and anthroposophic medicine are considered to be part of the specialized therapy options described in the German Medicines Act and have been granted special approval status [8]. Recent estimates about the drug market in Germany show that herbal medicines represent approximately $30 \%$ of over-the-counter medications [9].
However, the use of herbal medicine varies widely across Europe. A single medicinal plant may be regarded as an herbal medicine, food, functional food, or dietary supplement in different countries, depending on each country's national regulations on different medicines [5]. Although strict rules on the quality and quantity of the ingredients of herbal medicines and their labeling apply to herbal medicines, the same does not apply to food products and dietary supplements, making the market for herbal products extremely diverse. To obtain authorization from the relevant national drug authority to market a product as a medicinal product, herbal medicines and herbal medicinal products require a full quality dossier, as well as evidence of efficacy and safety, either based on clinical trials or from scientific literature or bibliographic data [10-12]. Dietary supplements and food products, on the other hand, are not the responsibility of drug approval authorities, so that there are no rules regarding evidence of their quality, efficacy, and safety. Dietary and food supplements involve concentrated nutrients or other substances with a nutritional or physiological effect that are sold in "doses", i.e., in the form of tablets or capsules, and are regulated as foodstuffs [13]. Unfortunately, it is not always obvious if an herbal product is being marketed as food or as a medicinal product. For example, peppermint leaves used to prepare an herbal infusion can be marketed as a foodstuff or as an herbal medicine. To the best of the authors' knowledge, there is no definition of an herbal product that is independent of its purpose as a medicinal product or food. The heterogeneity among herbal products increases the difficulty for healthcare professionals when counseling patients, as well as the difficulty patients have when choosing a safe but also potent herbal medicine. 
Phytotherapy, or treatment with herbal medicine, includes the use of potent plants that may cause side effects or interact with drugs $[14,15]$. Caution is needed, particularly when herbal products are used to treat side effects associated with cancer therapy, as herbal medicines may interact with the chemotherapeutic agents, for example, by increasing the toxicity or reducing the effectiveness of the cancer therapy. Novel therapy approaches available to treat gynecologic cancers, for example, poly(adenosine diphosphate ribose) polymerase (PARP) inhibitors, may be affected by interactions caused by cytochrome P450 (CYP) enzymes [16, 17]. Some recommendations therefore go as far as discouraging the use of herbal supplements altogether [18]. In addition, patients often do not disclose their use of CAM and herbal medicines to the physicians treating them [4, 19-24].

In order to provide optimal therapy to patients with gynecologic cancer and also take their personal wish to use CAM and herbal medicine into account, it is important to know which herbal medicines are used by patients with gynecologic cancer and whether there are any differences in the use of herbal medicine by gynecologic carcinoma patients and by heathy persons.

\section{Methods}

\section{Description of study}

The study was approved by the local ethics committee (reference number 255_16 B) and the study protocol complied with the Declaration of Helsinki. All of the participants provided written informed consent. This retrospective cross-sectional study was conducted at the Department of Gynecology and Obstetrics of Erlangen University Hospital.

Between December 2016 and January 2017, a standardized questionnaire on the use of herbal products was developed and validated in a group of 29 patients receiving follow-up care after breast cancer and five patients from the hospital's integrative medicine consultancy service (see questionnaire in the Supporting Information 1). These patients received the original questionnaire and were asked to evaluate it on a separate evaluation sheet which included items on "comprehensibility," "complexity," "time required for completion," and whether the patients "felt comfortable answering the questionnaire" or had any suggested improvements. Minor revisions to the questionnaire were adopted after the validation phase and before the questionnaire was used for the final survey.

The cross-sectional survey took place between March 2017 and December 2018. The questionnaire was administered to female patients with breast cancer or gynecologic cancer, and to healthy women attending appointments for preventive medical check-ups. A total of 868 questionnaires were returned. Four questionnaires had to be excluded, as they had been answered by the same patient. To be eligible for inclusion in the analysis, participants had to have a diagnosis of gynecologic carcinoma or be a healthy woman attending a check-up. A total of 413 data sets were available for analysis. Data of breast cancer patients were not included in this evaluation but will be provided in a separate analysis.
The participants' clinical records were used to collect information on patient and tumor characteristics. All of the participants completed the validated questionnaire on the use of plant products. The questionnaire comprised one general question on the plants used by the participants and included five items with questions on the type of use, duration of use, reasons for use, as well as information on the medical use of specific plant products (Supporting Information 1). For the purposes of the questionnaire, a plant product or herbal product was defined as any processed product derived from plants, irrespective of its regulatory status. Both herbal medicines and food products or dietary supplements were included.

\section{Statistical considerations}

Statistical evaluation was performed using descriptive statistics and included calculations of absolute numbers, percentages, means, and standard deviations. The group of patients with gynecologic cancer was compared with the group of healthy controls. Analysis of variance (ANOVA) was used to assess age differences between the groups. A logistic regression model adjusted for age was used to assess differences in plant use between the groups. Risk ratios for numbers of plants used and sources of recommendations were assessed using a Poisson regression model. A p value of 0.05 was set as the threshold for significance. All calculations were carried out using the statistics program IBM SPSS, version 21 (IBM Corporation, Armonk, New York, USA). Missing data were excluded from the analysis.

\section{Results}

\section{Characteristics of participants}

A total of 413 participants were included in the analysis: 201 in the group with gynecologic carcinomas and 212 in the group of healthy controls. The mean age was $57.2( \pm 13.9)$ years in the group of cancer patients and $49.4( \pm 13.5)$ years in the group of healthy controls. The healthy participants were significantly younger than the cancer patients. The majority of cancer patients had ovarian cancer $(43 \%)$ or were in a post-treatment setting (45\%). At the time of completing the survey, 20 patients (25\%) were receiving chemotherapy, 26 patients (13\%) were receiving targeted therapy, and 139 patients (69\%) were not receiving systemic therapy. - Table 1 lists the participants' characteristics.

\section{Use of plant products}

There were 138 users of plant products (69\%) among the patients with gynecologic cancer. By comparison, more healthy participants used plant products $(n=172,81 \%)$. The difference was statistically significant. The plants most commonly used by both groups were ginger, peppermint, green tea, chamomile, fennel, sage, stinging nettle, arnica, caraway, and olive. The healthy participants used sage $(p=0.003)$, caraway $(p=0.002)$, and olive $(p=0.004)$ more often. In comparison with the healthy controls, patients with gynecologic cancer used fewer plant products $(\mathrm{RR}=0.79 ; 95 \% \mathrm{Cl} 0.70-0.89)$. No specific plant was used more often by patients with gynecologic cancer compared with healthy 
- Table 1 Characteristics of patients and healthy controls.

\begin{tabular}{|c|c|c|c|}
\hline & $\begin{array}{l}\text { Gynecologic } \\
\text { cancer } \\
\text { patients } \\
(\mathbf{n}=201)\end{array}$ & $\begin{array}{l}\text { Healthy } \\
\text { controls } \\
(n=212)\end{array}$ & p \\
\hline Age (mean $\pm S D$, years) & $57.2 \pm 13.9$ & $49.4 \pm 13.5$ & $<0.001^{\#}$ \\
\hline \multicolumn{4}{|l|}{ Tumor location* } \\
\hline - ovarian cancer (n, \%) & $86(43 \%)$ & & \\
\hline - cervical cancer (n, \%) & $33(16 \%)$ & & \\
\hline - endometrial cancer (n, \%) & $46(23 \%)$ & & \\
\hline - vulvar cancer (n, \%) & $21(10 \%)$ & & \\
\hline $\begin{array}{l}\text { - other gynecologic cancer } \\
(\mathrm{n}, \%)\end{array}$ & $19(10 \%)$ & & \\
\hline \multicolumn{4}{|l|}{ Disease stage } \\
\hline - initial disease (n, \%) & $153(76 \%)$ & & \\
\hline - recurrent disease (n, \%) & $8(4 \%)$ & & \\
\hline - metastasis (n, \%) & $40(20 \%)$ & & \\
\hline \multicolumn{4}{|l|}{ Therapy stage } \\
\hline - neoadjuvant (n, \%) & $22(11 \%)$ & & \\
\hline - adjuvant (n,\%) & $41(20 \%)$ & & \\
\hline - palliative (n, \%) & $48(24 \%)$ & & \\
\hline - post-treatment (n, \%) & $90(45 \%)$ & & \\
\hline \multicolumn{4}{|l|}{ Current therapy* } \\
\hline " chemotherapy (n, \%) & $50(25 \%)$ & & \\
\hline - endocrine therapy (n, \%) & $3(2 \%)$ & & \\
\hline - targeted therapy (n, \%) & $26(13 \%)$ & & \\
\hline - bisphosphonates (n, \%) & $6(3 \%)$ & & \\
\hline - no systemic therapy (n, \%) & $139(69 \%)$ & & \\
\hline
\end{tabular}

participants. - Table 2 provides a summary of the plants used by healthy controls and cancer patients.

The mean number of plant products used by cancer patients was $3.3( \pm 2.7)$, compared to $4.1( \pm 3.1)$ used by healthy participants. While $70 \%(n=319)$ of the plants were used over a longer period of time (more than 8 weeks) by oncologic patients, $55 \%$ $(n=387)$ of the plants were used for more than 8 weeks by healthy participants. The number of plants used for a short period (less than 8 weeks) was 117 (26\%) for patients with gynecologic cancer and 293 (41\%) for healthy participants. Although there were no significant differences between the two groups with regard to the long-term use of plant products ( $R R=0.97 ; 95 \% \mathrm{Cl}$ $0.83-1.13)$, more healthy participants used plant products for short periods $(\mathrm{RR}=0.43 ; 95 \% \mathrm{Cl} 0.35-0.54)$.

\section{Use of plant products for medicinal purposes}

The number of healthy participants who used plants for medicinal purposes was significantly higher compared to patients with gynecologic cancer. While $56 \%$ of the healthy participants ( $n=119$ ) stated that they used plants for medicinal purposes, only $40 \%$ of patients with gynecologic cancer $(n=81)$ did so
- Table 2 General use of plants by patients with gynecologic cancer and healthy controls.

\begin{tabular}{|l|l|l|l|}
\hline & $\begin{array}{l}\text { Gynecologic } \\
\text { cancer } \\
\text { patients } \\
\text { (n= 201) }\end{array}$ & $\begin{array}{l}\text { Healthy } \\
\text { controls } \\
\text { (n= 212) }\end{array}$ & $\mathbf{p}^{*}$ \\
\hline $\begin{array}{l}\text { Individuals using plant products } \\
\text { (n, \%) }\end{array}$ & $138(69 \%)$ & $172(81 \%)$ & 0.011 \\
\hline Plants used (n, \%) & & & \\
\hline - Zingiber officinale (ginger) & $57(28 \%)$ & $92(43 \%)$ & 0.088 \\
\hline - Mentha piperita (peppermint) & $59(29 \%)$ & $82(39 \%)$ & 0.144 \\
\hline - Camellia sinensis (tea) & $37(18 \%)$ & $60(28 \%)$ & 0.271 \\
\hline - Matricaria recutita & $39(19 \%)$ & $62(29 \%)$ & 0.092 \\
\hline (chamomile) & $34(17 \%)$ & $53(25 \%)$ & 0.177 \\
\hline - Foeniculum vulgare (fennel) & $24(12 \%)$ & $55(26 \%)$ & 0.003 \\
\hline - Salvia officinalis (sage) & $26(13 \%)$ & $37(17 \%)$ & 0.687 \\
\hline - Urtica dioica (nettle) & $21(10 \%)$ & $31(15 \%)$ & 0.908 \\
\hline - Arnica montana (arnica) & $16(8 \%)$ & $33(16 \%)$ & 0.020 \\
\hline - Carum carvi (caraway) & $13(6 \%)$ & $37(17 \%)$ & 0.004 \\
\hline - Olea europaea (olive) & & & \\
\hline * Logistic regression model adjusted for age. & & \\
\hline $\begin{array}{l}\text { Multiple responses were allowed. } \\
\text { bold: p<0.05 }\end{array}$ & & & \\
\hline
\end{tabular}

$(p=0.027)$. The plants used most often for medicinal purposes were arnica, ginger, sage, chamomile, fennel, peppermint, valerian, stinging nettle, caraway, and calendula. No statistically significant differences were observed between the groups with regard to individual plants, with the exception of fennel $(p=0.021)$ and peppermint $(p=0.014)$, which were used more often by healthy participants. Patients with gynecologic cancer used fewer plant products for medicinal purposes than healthy participants ( RR $=0.71 ; 95 \% \mathrm{Cl} 0.58-0.85)$. - Table 3 lists the plants used for medicinal purposes.

The most common symptoms treated with plant products are listed in > Table 4. Respiratory complaints and common colds were the symptoms reported most often by healthy participants ( $n=58,49 \%)$, followed by gastrointestinal complaints $(n=31$, $26 \%$ ), and anxiety or trouble sleeping ( $n=26,22 \%)$. The most common symptoms reported by cancer patients were gastrointestinal complaints $(n=14,17 \%)$, anxiety or trouble sleeping ( $n=13,16 \%$ ), as well as cancer, impaired immune system, and respiratory complaints/common cold (each $n=10,12 \%$ ).

\section{Sources of recommendations for plant products}

The numbers of plant products recommended for medicinal purposes by physicians, pharmacists, alternative practitioners, family and friends, internet/newspapers, or other sources are listed in - Table 5. Participants mainly received their information about herbal medicine from family and friends. No statistically significant differences between the two groups were observed with regard to the number of plants recommended by other sources of information. 
- Table 3 Use of plants for medicinal purposes by patients with gynecologic cancer and healthy controls.

\begin{tabular}{|l|c|c|c|}
\hline & $\begin{array}{l}\text { Gynecologic } \\
\text { cancer } \\
\text { patients } \\
\text { (n= 201) }\end{array}$ & $\begin{array}{l}\text { Healthy } \\
\text { controls } \\
\text { (n= 212) }\end{array}$ & p* \\
\hline $\begin{array}{l}\text { Individuals using plant products } \\
\text { (n, \%) }\end{array}$ & $81(40 \%)$ & $119(56 \%)$ & 0.027 \\
\hline Plants used (n, \%) & & & \\
\hline - Arnica montana (arnica) & $20(10 \%)$ & $31(15 \%)$ & 0.998 \\
\hline - Zingiber officinale (ginger) & $11(5 \%)$ & $31(15 \%)$ & 0.075 \\
\hline - Salvia officinalis (sage) & $8(4 \%)$ & $35(17 \%)$ & 0.745 \\
\hline - Matricaria recutita & $13(6 \%)$ & $32(15 \%)$ & 0.095 \\
\hline (chamomile) & $9(5 \%)$ & $27(13 \%)$ & 0.021 \\
\hline - Foeniculum vulgare (fennel) & $7(3 \%)$ & $27(13 \%)$ & 0.014 \\
\hline - Mentha piperita (peppermint) & $11(5 \%)$ & $16(8 \%)$ & 0.999 \\
\hline - Valeriana officinalis (valerian) & $11(5 \%)$ & $20(9 \%)$ & 0.528 \\
\hline - Urtica dioica (nettle) & $7(3 \%)$ & $18(8 \%)$ & 0.412 \\
\hline - Carum carvi (caraway) & $9(5 \%)$ & $15(7 \%)$ & 0.725 \\
\hline - Calendula officinalis \\
(pot marigold)
\end{tabular}

\section{Discussion}

Although herbal medicine is one of the most popular types of CAM used by patients with gynecologic cancer with a prevalence of up to $23 \%$, little is known about the actual herbal products or plants used by these patients [2]. To the best of the authors' knowledge, this is the first study that has focused exclusively on patients with gynecologic cancer and their use of herbal products or herbal medicines.

The study showed that cancer patients use herbal medicine less frequently than healthy persons. The use of herbal products specifically for medicinal purposes is more common among healthy individuals. However, patients with gynecologic cancer usually use herbal medicinal products for a longer period (> 8 weeks). The major source of information about herbal medicines in both groups was family and friends.

The present study consisted of a large group with a total of 413 participants, of whom 201 were patients with gynecologic cancers. In Germany, the annual incidence of gynecologic cancers is around 26000 , which amounts to around $10 \%$ of all cancer diagnoses [25]. Carcinomas of the uterus are the most common type of gynecologic cancer in Germany [26-28]. However, the majority of cancer patients in our study had ovarian cancer. Earlier studies have shown that patients with ovarian cancer are particularly likely to use CAM, including herbal medicine [2]. A possible explanation is that the use of herbal medicine may be associated with the use of systemic treatment. In addition to surgery, patients with ovarian cancer often also receive systemic treatments
- Table 4 Top 15 symptoms treated with plant products by patients with gynecologic cancer and healthy controls.

\begin{tabular}{|l|l|l|l|}
\hline & $\begin{array}{l}\text { Gynecologic } \\
\text { cancer } \\
\text { patients } \\
\text { (n=81) }\end{array}$ & $\begin{array}{l}\text { Healthy } \\
\text { controls } \\
\text { (n=119) }\end{array}$ & p \\
\hline $\begin{array}{l}\text { Respiratory complaints and } \\
\text { common cold }\end{array}$ & $10(12 \%)$ & $58(49 \%)$ & $<0.001$ \\
\hline Gastrointestinal complaints & $14(17 \%)$ & $31(26 \%)$ & 0.169 \\
\hline Anxiety/trouble sleeping & $13(16 \%)$ & $26(22 \%)$ & 0.061 \\
\hline Cancer & $10(12 \%)$ & $1(1 \%)$ & 0.011 \\
\hline Impaired immune system & $10(12 \%)$ & $4(3 \%)$ & 0.026 \\
\hline Impaired wound healing & $9(11 \%)$ & $13(11 \%)$ & 0.946 \\
\hline Musculoskeletal complaints & $5(6 \%)$ & $17(14 \%)$ & 0.089 \\
\hline Dry skin & $4(5 \%)$ & $6(5 \%)$ & 0.765 \\
\hline Swelling/edema & $6(7 \%)$ & $8(7 \%)$ & 0.539 \\
\hline Flatulence & $5(6 \%)$ & $5(4 \%)$ & 0.975 \\
\hline Hepatobiliary complaints & $2(2 \%)$ & $2(2 \%)$ & 0.625 \\
\hline Nausea & $3(4 \%)$ & $7(6 \%)$ & 0.452 \\
\hline Menopausal complaints/ & $2(2 \%)$ & $2(2 \%)$ & 0.770 \\
\hline hot flashes & $4(5 \%)$ & $3(3 \%)$ & 0.404 \\
\hline Urinary tract complaints & $2(2 \%)$ & $2(2 \%)$ & 0.923 \\
\hline $\begin{array}{l}\text { Improvement of general } \\
\text { condition }\end{array}$ & & & \\
\hline & & & \\
\hline
\end{tabular}

Only users of plant products for medicinal purposes were included in the analysis. Multiple responses were allowed. ${ }^{*}$ Logistic regression model adjusted for age.

bold: $\mathrm{p}<0.05$

- Table 5 Sources of recommendations of medicinal plant products to patients with gynecologic cancer and healthy controls.

\begin{tabular}{|l|l|l|}
\hline & $\begin{array}{l}\text { Gynecologic } \\
\text { cancer patients } \\
\mathbf{n}(\%)\end{array}$ & $\begin{array}{l}\text { Healthy } \\
\text { controls } \\
\mathbf{n}(\%)\end{array}$ \\
\hline Total medicinal plant products & 171 & 357 \\
\hline Physician & $41(24 \%)$ & $108(30 \%)$ \\
\hline Pharmacist & $23(13 \%)$ & $21(6 \%)$ \\
\hline Alternative practitioner & $23(13 \%)$ & $60(17 \%)$ \\
\hline Family/friends & $80(47 \%)$ & $191(54 \%)$ \\
\hline Internet/newspapers & $37(22 \%)$ & $83(23 \%)$ \\
\hline Other & $23(13 \%)$ & $58(16 \%)$ \\
\hline
\end{tabular}

Multiple responses allowed. Only individuals using medicinal plant products were included in the analysis.

such as chemotherapy or novel therapies such as treatment with PARP inhibitors $[17,29]$, which are prone to have side effects. Treatment for the side effects of cancer therapy is one of the most common reasons for using CAM, including herbal medicine [1,2]. 
The mean age of the cancer patients included in this survey was 57 years, 10 years older than the group of healthy participants. Although gynecologic cancers such as ovarian cancer may occur in patients younger than 45 , the probability of developing cancer generally increases with age [30].

The survey investigated the use of plant products in patients with gynecologic cancers and compared it with that of controls. For the purposes of this study, a plant product was considered to be any product containing a plant as a major ingredient, regardless of its regulatory status, e.g., food products, dietary supplements or herbal medicines, and irrespective of the number of plants contained in the product. To the best of the authors' knowledge, there is no standardized definition of an herbal product. The definition depends on the regulatory context which determines how the product may be sold. In Germany, there are different ways in which herbal products are used, for example as a foodstuff, an herbal medicine or as part of a dietary supplement. While herbal medicines must comply with different quality standards and safety parameters, this level of control is not required for foodstuffs. The EMA defines an herbal medicinal product as "any medicinal product, exclusively containing as active ingredients one or more herbal substances, one or more herbal preparations, or a combination of the two" and an herbal substance as "all mainly whole, fragmented or cut plants, plant parts, algae, fungi, lichen in an unprocessed, usually dried, form, but sometimes fresh. Certain exudates that have not been subjected to a specific treatment are also considered to be herbal substances", while herbal preparations are "preparations obtained by subjecting herbal substances to treatments such as extraction, distillation, expression, fractionation, purification, concentration or fermentation. These include comminuted or powdered herbal substances, tinctures, extracts, essential oils, expressed juices and processed exudates" [31]. When evaluated in the context of food, botanicals are defined as "all botanical materials (e.g. whole, fragmented or cut plants, plant parts, algae, fungi and lichens)" and botanical preparations are "all preparations obtained from botanicals by various processes (e.g. pressing, squeezing, extraction, fractionation, distillation, concentration, drying up and fermentation)." [32] Which of these definitions applies, depends on the purpose for which these herbal products are sold. However, this differentiation may not always be clear to the consumer of the product. The WHO provides a definition for a finished herbal product as follows: "Finished herbal products consist of one or more herbal preparations made from one or more herbs (i.e. from different herbal preparations made of the same plant as well as herbal preparations from different plants. Products containing different plant materials are called "mixture herbal products"). Finished herbal products and mixture herbal products may contain excipients in addition to the active ingredients. However, finished products or mixture herbal products to which chemically defined active substances have been added, including synthetic compounds and/or isolated constituents from herbal materials, are not considered to be "herbal“.” [33]. The WHO document also states that "Herbal preparations are the basis for finished herbal products and may include comminuted or powdered herbal materials, or extracts, tinctures and fatty oils of herbal materials. They are produced by extraction, fractionation, purification, con- centration or other physical or biological processes. They also include preparations made by steeping or heating herbal materials in alcoholic beverages and/or honey, or in other materials." [33]. The subjects in our study were expected to complete the questionnaire themselves without assistance. Therefore, we cannot assume that our study subjects were familiar with the correct definition of an herbal product, which depends on its regulatory context. Hence, we opted for a more feasible and less complex definition and summarized all plant-derived products as herbal products.

Use of herbal products was high in both groups. A review focusing on herbal medicine use among adult cancer patients in the United Kingdom estimated that between $3.1 \%$ and $21.8 \%$ of the patients used phytotherapy [5]. The figure in the present study was considerably higher. Even when only evaluating the use of plant products for medicinal purposes, $40 \%$ of cancer patients reported using herbal medicines. CAM use, including the use of herbal medicines, is often associated with female cancer patients, younger age, and higher socioeconomic status [34-36].

Herbal products are generally considered to be safe, and the level of acceptance for them in the general population is high. However, healthy participants in this study used plant products considerably more often than patients with gynecologic cancer. Possible reasons for this may be that cancer patients are cautious about self-medication and fear potential drug interactions and side effects [37]. Cancer patients may also have already received several other medications and therefore did not wish to take any more pills. Many doctors also discourage the use of herbal medicines due to a fear of interaction with drug therapy [15].

Apart from sage, caraway, and olive, there were no differences between the two groups with regard to the use of specific medicinal plants. Healthy participants used these products more often than cancer patients. The plants were commonly used as food products, as spices or herbal infusions, and are characterized by their distinctive aromatic smell and taste. Similar findings were observed for the use of plants for medicinal purposes. Healthy participants used peppermint and fennel, both easily identified by their characteristic smell and taste, significantly more often than patients with gynecologic cancer. Patients receiving chemotherapy often have gastrointestinal symptoms with disruption of the mucosal membranes and become sensitive to tastes and smells [35]. These patients may therefore avoid using strong-tasting or strong-smelling plant products such as sage, caraway, fennel, or peppermint.

The plants most commonly used for medicinal purposes were arnica, ginger, sage, and chamomile, which are common remedies for general complaints such as wounds, gastrointestinal symptoms, respiratory symptoms, and inflammations [38, 39].

This is consistent with the symptoms reported by the survey participants for which they used herbal medicines. The most common symptoms treated with herbal remedies were respiratory complaints or common cold, gastrointestinal complaints, and anxiety. All of these symptoms are regular indications for treatment with over-the-counter medicines $[39,40]$. Generally, there were few differences in the indications for using herbal medicines between the two groups. However, some of the reasons given for the medicinal use of plant products differed between the groups. 
Whereas healthy participants turned to herbal medicine to treat general symptoms/general conditions, cancer patients' reasons included cancer symptoms and boosting their immune system. This is unsurprising, as immunodeficiency is one of the most common issues that cancer patients face during treatment [35]. Similar observations have been made in other studies of cancer patients, in which mostly nonspecific reasons such as improving health or fighting cancer have been reported [5]. Significantly fewer cancer patients used herbal medicine to treat common colds or respiratory symptoms.

The present study found that patients with gynecologic cancer used plants less often than healthy participants. However, when cancer patients used herbal products, they persisted in using them a lot longer. Although there were no differences between healthy participants and cancer patients with regard to the numbers of plants used for more than 8 weeks, cancer patients used less than half as many plants for short periods of less than 8 weeks. One possible explanation for this could be that cancer patients are motivated to maintain a constant treatment regimen. In addition, patients with gynecologic cancer may suffer long-term side effects of cancer treatment and therefore require long-term care.

Women using herbal supplements and CAM products have previously reported that friends or magazines were their most important sources of information regarding plant products [41]. This finding is in accordance with the present study. It is notable that for cancer patients, physicians were not the first source they consulted about herbal medicine. Only about half of the patients with gynecologic cancer disclosed their use of CAM, including herbal medicine, to their treating physician $[19,42,43]$. Reasons for this given by patients ranged from a perception that physicians are not interested in patients' self-medication to a fear that doctors might discourage the use of herbal medicines [41]. On the other hand, many patients may wish to receive counseling on integrative medicine from their treating physician [4, 37, 44]. This shows that it is important for doctors to be aware that patients are using herbal medicines, and doctors should encourage their patients to tell them which herbal products they are using. Some herbal products have been reported to have an influence on cancer or to interact with cancer treatment [16]. For example, phytoestrogens from red clover or black cohosh may interact with hormone-sensitive cancers, and St. John's wort is a known CYP3A4 inducer that affects orally administered drugs [15,45]. Other plants, however, may be safely administered even while patients are receiving systemic therapy and may therefore be an attractive option to treat therapy-associated side effects or symptoms.

The present study has several strengths and limitations. It should be borne in mind that it was a cross-sectional study. As it was a one time survey, no follow-up data on the participants was available. The survey was also conducted only at the Department of Gynecology and Obstetrics of Erlangen University Hospital. Cancer patients or healthy persons being treated in an outpatient setting were not included in the study. It should also be noted that the two groups differed with regard to age, with the cancer patients being on average about 10 years older than the healthy participants.
However, the study also has several strengths. It was possible to include a large number of participants in both groups, and the drop-out rate was very low. Data were collected using a standardized questionnaire, which was validated for comprehensibility and complexity. The group of cancer patients included in the survey included all stages of disease and treatment and can therefore be regarded as representative. Usually, the use of herbal medicines is not covered in common hospital questionnaires and little data is available on the use of herbal medicine by patients with gynecologic cancer.

Gynecologic oncologists should be aware of their patients' use of herbal medicines and their motivations so that they can provide informed counseling and ensure their patients' safety during cancer treatment.

\section{Conclusion}

This study shows that patients with gynecologic cancer as well as healthy persons are regular users of herbal products and herbal medicines. However, patients with gynecologic cancer use herbal medicines significantly less than healthy individuals. The reasons given for using herbal medicines usually involved treatment of general symptoms, but cancer patients also use them to treat cancer-related symptoms. This should be taken into consideration by gynecologic oncologists, and patients should be actively encouraged to disclose their use of herbal products to their physicians. It is only when everyone involved has all the necessary information that safe therapy decisions can made which take the patients' needs into consideration and may improve cancer treatment.

This is one of the first studies to carry out a systematic evaluation of gynecologic cancer patients' use of herbal products in comparison with healthy persons. The findings will need to be confirmed in further studies.

\section{Acknowledgements}

We are grateful to all of the patients, to the research personnel involved, and to the hospital staff. The contribution of SK to this publication was made in partial fulfillment of the requirements for obtaining the degree of Doctor of Medicine. Parts of the research published here were used for her doctoral thesis submitted to the Medical Faculty of Friedrich Alexander University of Erlangen-Nuremberg (FAU).

\section{Conflict of Interest}

AKT received a research grant from Phytolab $\mathrm{GmbH} \&$ Co KG. CCH has received honoraria from Roche and Novartis. PAF reports personal fees from Novartis, grants from BioNtech, personal fees from Pfizer, personal fees from Daiichi Sankyo, personal fees from AstraZeneca, personal fees from Eisai, personal fees from Merck Sharp \& Dohme, grants from Cepheid, personal fees from Lilly, personal fees from Pierre Fabre and personal fees from Seattle Genetics. All of the other authors declare that they have no conflicts of interest. 


\section{References}

[1] Molassiotis A, Browall M, Milovics L et al. Complementary and alternative medicine use in patients with gynecological cancers in Europe. Int J Gynecol Cancer 2006; 16 (Suppl. 1): 219-224

[2] Swisher EM, Cohn DE, Goff BA et al. Use of complementary and alternative medicine among women with gynecologic cancers. Gynecol Oncol 2002; 84: 363-367

[3] Navo MA, Phan J, Vaughan C et al. An assessment of the utilization of complementary and alternative medication in women with gynecologic or breast malignancies. J Clin Oncol 2004; 22: 671-677

[4] Ben-Arye E, Schiff E, Steiner M et al. Attitudes of Patients With Gynecological and Breast Cancer Toward Integration of Complementary Medicine in Cancer Care. Int J Gynecol Cancer 2012; 22: 146-153

[5] Gratus C, Wilson S, Greenfield SM et al. The use of herbal medicines by people with cancer: a qualitative study. BMC Complement Altern Med 2009; 9: 14

[6] Goldstein MS, Lee JH, Ballard-Barbash R et al. The use and perceived benefit of complementary and alternative medicine among Californians with cancer. Psychooncology 2008; 17: 19-25

[7] World Health Organization (WHO). Traditional Medicine: Definitions. 2017. Accessed June 30, 2020 at: http://www.who.int/medicines/areas/ traditional/definitions/en/

[8] Arzneimittelgesetz (AMG). 1967. Medicinal Products Act in the version published on 12 December 2005 (Federal Law Gazette [BGBI.]) Part I p. 3394, last amended by Article 11 of the Act of 6 May 2019 (Federal Law Gazette I p.646)

[9] Bundesverband der Arzneimittel-Hersteller e.V. (BAH). Der Arzneimittelmarkt in Deutschland 2019. The German Pharmaceutical Market 2019. 2020. Accessed August 11, 2020 at: https://www.bah-bonn.de/ publikationen/zahlen-fakten/

[10] European Medicines Agency, Committee on Herbal Medicinal Products. Guideline on the use of the CTD format in the preparation of a registration application for traditional herbal medicinal products. 2016. EMA/ HMPC/71049/2007 Rev. 2. Accessed November 17, 2020 at: https:// www.ema.europa.eu/en/documents/scientific-guideline/guideline-usectd-format-preparation-registration-application-traditional-herbalmedicinal-products_en.pdf

[11] European Medicines Agency, Committee on Herbal Medicinal Products. Guideline on non-clinical documentation in applications for marketing authorisation/registration of well-established and traditional herbal medicinal products. 2018. EMEA/HMPC/32116/2005 Rev.1. Accessed November 17, 2020 at: https://www.ema.europa.eu/en/documents/ scientific-guideline/guideline-non-clinical-documentation-applicationsmarketing-authorisation/registration-well-established-traditionalherbal-medicinal-products-revision-1_en.pdf

[12] European Medicines Agency, Committee on Herbal Medicinal Products, Committee for Medicinal Products for Human Use, Committee for Medicinal Products for Veterinary Use. Guideline on quality of herbal medicinal products/traditional herbal medicinal products. 2011. EMA/ CPMP/QWP/2819/00 Rev. 2, EMA/CVMP/814/00 Rev. 2, EMA/HMPC/ 201116/2005 Rev. 2. Accessed November 17, 2020 at: https://www. ema.europa.eu/en/documents/scientific-guideline/guideline-qualityherbal-medicinal-products-traditional-herbal-medicinal-productsrevision-2_en.pdf

[13] European Parliament and Council. Directive 2002/46/EC of the European Parliament and of the Council of 10 June 2002 on the approximation of the laws of the Member States relating to food supplements (Text with EEA relevance). Official Journal of the European Communities 2002. L183, 12/07/2002 P. 0051-0057

[14] Arslan D, Tural D, Akar E. Herbal administration and interaction of cancer treatment. J Palliat Med 2013; 16: 1466-1476
[15] Izzo AA, Ernst E. Interactions between herbal medicines and prescribed drugs: an updated systematic review. Drugs 2009; 69: 1777-1798

[16] Clairet AL, Boiteux-Jurain M, Curtit E et al. Interaction between phytotherapy and oral anticancer agents: prospective study and literature review. Med Oncol 2019; 36: 45

[17] Hartkopf AD, Müller V, Wöckel A et al. Translational Highlights in Breast and Ovarian Cancer 2019 - Immunotherapy, DNA Repair, PI3K Inhibition and CDK4/6 Therapy. Geburtshilfe Frauenheilkd 2019; 79: 1309-1319

[18] Deng G, Cassileth BR, Yeung KS. Complementary therapies for cancerrelated symptoms. J Support Oncol 2004; 2: 419-426; discussion 427429

[19] Shim JM, Schneider J, Curlin FA. Patterns of User Disclosure of Complementary and Alternative Medicine (CAM) Use. Med Care 2014; 52: 704-708

[20] Drozdoff L, Klein E, Kalder M et al. Potential Interactions of Biologically Based Complementary Medicine in Gynecological Oncology. Integr Cancer Ther 2019; 18: 1534735419846392

[21] Drozdoff L, Klein E, Kiechle M et al. Use of biologically-based complementary medicine in breast and gynecological cancer patients during systemic therapy. BMC Complement Altern Med 2018; 18: 259

[22] Henf A, Wesselmann S, Huthmann D et al.; on behalf of the Working Group Prevention and Intergrative Oncology of the German Cancer Society J. Complementary and Alternative Medicine in German Cancer Centers. Oncol Res Treat 2014; 37: 390-394

[23] Schuerger N, Klein E, Hapfelmeier A et al. Evaluating the Demand for Integrative Medicine Practices in Breast and Gynecological Cancer Patients. Breast Care 2019; 14: 35-40

[24] Zeller T, Muenstedt K, Stoll C et al. Potential interactions of complementary and alternative medicine with cancer therapy in outpatients with gynecological cancer in a comprehensive cancer center. J Cancer Res Clin Oncol 2013; 139: 357-365

[25] Robert Koch-Institut (RKI). Bericht zum Krebsgeschehen in Deutschland. 2016. Accessed September 15, 2020 at: https://edoc.rki.de/handle/ 176904/3264

[26] Leitlinienprogramm Onkologie (Deutsche Krebsgesellschaft; Deutsche Krebshilfe; AWMF). S3-Leitlinie Diagnostik, Therapie und Nachsorge der Patientinnen mit Endometriumkarzinom Langversion 1.0. Interdisciplinary Diagnosis, Therapy and Follow-up of Patients with Endometrial Cancer. Guideline (S3-Level), Long Version 1.0. Arbeitsgemeinschaft der Wissenschaftlichen Medizinischen Fachgesellschaften e.V. (AWMF) e.V. 2018. Accessed June 15, 2020 at: https://www.awmf.org/uploads/ tx_szleitlinien/032-034OLI_S3_Endometriumkarzinom-DiagnostikTherpie-Nachsorge_2018-04.pdf

[27] Emons G, Steiner E, Vordermark D et al. Interdisciplinary Diagnosis, Therapy and Follow-up of Patients with Endometrial Cancer. Guideline (S3-Level, AWMF Registry Number 032/034-OL, April 2018) - Part 2 with Recommendations on the Therapy and Follow-up of Endometrial Cancer, Palliative Care, Psycho-oncological/Psychosocial Care/Rehabilitation/Patient Information and Healthcare Facilities. Geburtshilfe Frauenheilkd 2018; 78: 1089-1109

[28] Schnürch HG, Ackermann S, Alt-Radtke CD et al. Diagnosis, Therapy and Follow-up of Vaginal Cancer and Its Precursors. Guideline of the DGGC and the DKG (S2k-Level, AWMF Registry No. 032/042, October 2018). Geburtshilfe Frauenheilkd 2019; 79: 1060-1078

[29] Leitlinienprogramm Onkologie der AWMF, Deutschen Krebsgesellschaft e.V. und Deutschen Krebshilfe e.V. S3-Leitlinie Diagnostik, Therapie und Nachsorge maligner Ovarialtumoren. Interdisciplinary Diagnosis, Therapy and Follow-up of Patients with Ovarian Cancer. Guideline (S3-Level). Arbeitsgemeinschaft der Wissenschaftlichen Medizinischen Fachgesellschaften e.V. (AWMF) e.V. 2016. Accessed February 01, 2018 at: https://www.ago-online.de/fileadmin/downloads/leitlinien/ovar/S3Ovarialkarzinom-OL-Langversion.pdf 
[30] Barnes B, Kraywinkel K, Nowossadeck E, Schönfeld I, Starker A, Wienecke A, Wolf U. Bericht zum Krebsgeschehen in Deutschland 2016. Berlin: Robert Koch-Institut; 2016. Accessed September 15, 2020 at: https:// edoc.rki.de/handle/176904/3264

[31] European Parliament and Council. Directive 2004/24/EC of the European Parliament and of the Council of 31 March 2004 amending, as regards traditional herbal medicinal products, Directive 2001/83/EC on the Community code relating to medicinal products for human use. Official Journal of the European Union 2004. OJ L136, 30.4.2004, p. 85-90

[32] EFSA Scientific Committee. Guidance on safety assessment of botanicals and botanical preparations intended for use as ingredients in food supplements. EFSA Journal 2009; 7: 1249

[33] WHO Expert Committee on Specifications for Pharmaceutical Preparation. Annex $1 \mathrm{WHO}$ guidelines on good herbal processing practices for herbal medicines. WHO Technical Report Series, No 1010, Fifty-second report: 81-151. 2018. Accessed April 15, 2020 at: https://www.who. int/traditional-complementary-integrative-medicine/publications/ trs1010_annex1.pdf

[34] Corner J, Yardley J, Maher E] et al. Patterns of complementary and alternative medicine use among patients undergoing cancer treatment. Eur J Cancer Care (Engl) 2009; 18: 271-279

[35] Hack CC, Voiß P, Lange S et al. Local and Systemic Therapies for Breast Cancer Patients: Reducing Short-term Symptoms with the Methods of Integrative Medicine. Geburtshilfe Frauenheilkd 2015; 75: 675-682

[36] Molassiotis A, Scott JA, Kearney N et al. Complementary and alternative medicine use in breast cancer patients in Europe. Support Care Cancer 2006; 14: 260-267
[37] Wiedeck C, Klein E, Hapfelmeier A et al. Prävalenz und Prädiktoren für die Nicht-Anwendung komplementärmedizinischer Therapien bei Patientinnen mit Mamma- oder gynäkologischen Krebserkrankungen. Geburtshilfe Frauenheilkd 2018; 78: 616

[38] Barnes ], Anderson LA, Phillipson JD. Herbal Medicines. London, Chicago: Pharmaceutical Press; 2007

[39] Beitz R, Doren M, Knopf $\mathrm{H}$ et al. [Self-medication with over-the-counter (OTC) preparations in Germany]. Bundesgesundheitsblatt Gesundheitsforschung Gesundheitsschutz 2004; 47: 1043-1050

[40] Eickhoff C, Hammerlein A, Griese $\mathrm{N}$ et al. Nature and frequency of drugrelated problems in self-medication (over-the-counter drugs) in daily community pharmacy practice in Germany. Pharmacoepidemiol Drug Saf 2012; 21: 254-260

[41] Vickers KA, Jolly KB, Greenfield SM. Herbal medicine: women's views, knowledge and interaction with doctors: a qualitative study. BMC Complement Altern Med 2006; 6: 40

[42] Harrigan JT. Patient disclosure of the use of complementary and alternative medicine to their obstetrician/gynaecologist. J Obstet Gynaecol 2011; 31: 59-61

[43] Von Gruenigen VE, White LJ, Kirven MS et al. A comparison of complementary and alternative medicine use by gynecology and gynecologic oncology patients. Int J Gynecol Cancer 2001; 11: 205-209

[44] Hack CC, Fasching PA, Fehm T et al. Interest in Integrative Medicine Among Postmenopausal Hormone Receptor-Positive Breast Cancer Patients in the EvAluate-TM Study. Integr Cancer Ther 2017; 16: 165-175

[45] Piersen CE. Phytoestrogens in botanical dietary supplements: implications for cancer. Integr Cancer Ther 2003; 2: 120-138 